\title{
Intrinsic Membrane Properties Underlying Spontaneous Tonic Firing in Neostriatal Cholinergic Interneurons
}

\author{
Ben D. Bennett, ${ }^{1}$ Joseph C. Callaway, ${ }^{2}$ and Charles J. Wilson ${ }^{1}$ \\ ${ }^{1}$ Cajal Neuroscience Research Center, Division of Life Sciences, University of Texas, San Antonio, Texas 78249 and \\ 2Department of Anatomy and Neurobiology, University of Tennessee, Memphis, Tennesse 38163
}

\begin{abstract}
Neostriatal cholinergic interneurons produce spontaneous tonic firing in the absence of synaptic input. Perforated patch recording and whole-cell recording combined with calcium imaging were used in vitro to identify the intrinsic membrane properties underlying endogenous excitability. Spontaneous firing was driven by the combined action of a sodium current and the hyperpolarization-activated cation current $\left(I_{h}\right)$, which together ensured that there was no zero current point in the subthreshold voltage range. Blockade of sodium channels or $I_{\mathrm{h}}$ established a stable subthreshold resting membrane potential. A tetrodotoxinsensitive region of negative slope conductance was observed between approximately $-60 \mathrm{mV}$ and threshold (approximately $-50 \mathrm{mV}$ ) and the h-current was activated at all subthreshold voltages.
\end{abstract}

Calcium imaging experiments revealed that there was minimal calcium influx at subthreshold membrane potentials but that action potentials produced elevations of calcium in both the soma and dendrites. Spike-triggered calcium entry shaped the falling phase of the action potential waveform and activated calcium-dependent potassium channels. Blockade of bigconductance channels caused spike broadening. Application of apamin, which blocks small-conductance channels, abolished the slow spike afterhyperpolarization (AHP) and caused a transition to burst firing.

In the absence of synaptic input, a range of tonic firing patterns are observed, suggesting that the characteristic spike sequences described for tonically active cholinergic neurons (TANs) recorded in vivo are intrinsic in origin. The pivotal role of the AHP in regulating spike patterning indicates that burst firing of TANs in vivo could arise from direct or indirect modulation of the AHP without requiring phasic synaptic input.

Key words: TANs; tonic firing; rhythmic bursting; spike sequences; irregular firing; sodium current; Ih
Single-unit recordings from awake, behaving primates have been used extensively to investigate the response properties of neostriatal cholinergic interneurons. The cholinergic cells are identified by their ongoing spiking activity and are consequently referred to as tonically active neurons (TANs). In contrast to spiny projection cells, TANs exhibit a pause in firing, which is phase-locked to sensory stimuli that trigger learned and rewarded movements (Crutcher and DeLong, 1984; Kimura et al., 1984; Liles, 1985; Schultz and Romo, 1988; Hikosaka et al., 1989; Apicella et al., 1991; Aosaki et al., 1994a,b, 1995; Raz et al., 1996; Watanabe and Kimura, 1998). The pause response emerges as the task is learned, which has led to the suggestion that the brief cessation in firing represents a physiological correlate of motor learning within the neostriatum (Graybiel et al., 1994). After systemic MPTP administration and the emergence of parkinsonian symptoms, the tonic firing of TANs is replaced by persistent oscillatory activity (Raz et al., 1996), and the pause response can no longer be triggered by sensory stimuli (Aosaki et al., 1994a). Together, these data suggest that spike timing in cholinergic cells is critically involved in both the normal functioning of the neostriatum and the pathophysiological processes that occur in parkinsonian states.

Intracellular in vivo recordings from neostriatal cholinergic interneurons have demonstrated that summation of only a few depolarizing synaptic potentials is sufficient to trigger spiking (Wilson et al., 1990). These data suggested that synaptic inputs are the principal determinants of action potential timing in cholinergic cells and have been interpreted as evidence that the tonic, irregular firing pattern of TANs recorded in vivo reflects the temporal

\footnotetext{
Received May 24, 2000; revised Sept. 1, 2000; accepted Sept. 5, 2000.

This study was supported by National Institutes of Health Grant NS37760. B.D.B. thanks Profs. S. T. Kitai and W. E. Armstrong for providing accommodation at The University of Tennessee, Memphis during January through March, 2000.

Correspondence should be addressed to Charles J. Wilson, Cajal Neuroscience Research Center, Division of Life Sciences, University of Texas, San Antonio, 6900 North Loop, 1604 West, San Antonio, TX 78249. E-mail: cjwilson@utsa.edu. Copyright (C) 2000 Society for Neuroscience 0270-6474/00/208493-11\$15.00/0
}

structure of the synaptic barrage (Wilson, 1993; Aosaki et al., 1995; Yan and Surmeier, 1997; Bennett and Wilson, 1998; Watanabe and Kimura, 1998). However, spontaneous firing has been commonly observed in cholinergic cells under conditions of reduced synaptic input both in vivo (Wilson et al., 1990) and in vitro (Bennett and Wilson, 1998; Calabresi et al., 1998; Lee et al., 1998). More recently, we found that, after pharmacological blockade of synaptic activity in vitro, cholinergic cells continued to fire, exhibiting spiking rates and patterns very similar to those of TANs recorded in vivo (Bennett and Wilson, 1999). It therefore seems likely that cholinergic cells possess ionic currents that confer endogenous excitability and that the spiking pattern of TANs reflects an interaction between synaptic input and the intrinsic properties of these cells. An understanding of the intrinsic mechanisms that are involved in spike generation and patterning is central to determining the origin of the pause response detected during unit recordings from TANs in vivo. Furthermore, the possibility that oscillatory activity observed in parkinsonian states might arise from alterations of the intrinsic membrane properties has potential clinical relevance because of the known efficacy of cholinergic antagonists in the treatment of Parkinson's disease (Hingtgen and Siemers, 1998; Schrag et al., 1999).

The objectives of this study were therefore to elucidate the intrinsic mechanisms that contribute to tonic firing and to investigate the consequences of perturbation of the different ionic currents that are involved in spike generation and patterning. With the exception of the calcium imaging experiments, the perforatedpatch configuration was used throughout to avoid alteration of the electrical properties of cholinergic cells that can occur during conventional whole-cell recording (Bennett and Wilson, 1999).

\section{MATERIALS AND METHODS}

Slice preparation. Brain slices were prepared using previously described procedures (Bennett and Wilson, 1998, 1999). Briefly, postnatal day 21-25 Sprague Dawley rats of either sex were deeply anesthetized with ketamine-xylazine and perfused via the ascending aorta with $30-50 \mathrm{ml}$ of ice-cold $\left(4^{\circ} \mathrm{C}\right)$ sucrose-substituted (Aghajanian and Rasmussen, 1989) saline con- 
taining (in mM): 230 sucrose, $2.5 \mathrm{KCl}, 1.25 \mathrm{NaH}_{2} \mathrm{PO}_{4}, 0.5 \mathrm{CaCl}_{2}, 10$ $\mathrm{MgSO}_{4}$, and 10 glucose. Coronal slices of $300 \mu \mathrm{m}$ thickness were then cut through the neostriatum with a vibrating blade microtome (Leica, Deerfield, IL) and transferred to a holding chamber containing artificial CSF (ACSF) $\left(25 \pm 2^{\circ} \mathrm{C}\right.$ ) of composition (in mM): $126 \mathrm{NaCl}, 2.5 \mathrm{KCl}, 1.25$ $\mathrm{NaH}_{2} \mathrm{PO}_{4}, 2 \mathrm{CaCl}_{2}, 2 \mathrm{MgSO}_{4}$, and 10 glucose. The ACSF was continuously oxygenated and recording commenced $1 \mathrm{hr}$ after the slicing procedure.

Visualized recording. Slices were transferred to the recording chamber and continuously perfused $(2-3 \mathrm{ml} / \mathrm{min})$ with oxygenated ACSF ( $35 \pm$ $\left.1^{\circ} \mathrm{C}\right)$. Neurons within the neostriatum were visualized using infrared differential interference contrast videomicroscopy (Dodt and Zieglgansberger, 1990; Stuart et al., 1993). Cholinergic cells were selected for recording on the basis of their characteristic somatodendritic morphology, and their identity was confirmed by their stereotyped responses to current injection (Jiang and North, 1991; Kawaguchi, 1992, 1993; Götz et al., 1997; Bennett and Wilson, 1998, 1999; Calabresi et al., 1998; Lee et al., 1998; Pisani et al., 1999, 2000). Recordings were obtained using the perforatedpatch technique (Horn and Marty, 1988; Korn and Horn, 1989) to avoid artifactual changes in the electrical properties of cholinergic cells that can occur during whole-cell recording (Bennett and Wilson, 1999). Gramicidin was used as the pore-forming agent (Myers and Haydon, 1972) because this was found to produce reliable perforation and long-lasting, stable recordings (Akaike and Harata, 1994; Rhee et al., 1994; Ebihara et al., 1995; Kyrozis and Reichling, 1995). Patch electrodes were prepared from thickwalled, unfilamented borosilicate glass (Warner Instruments, Hamden, CT) on a P-87 Brown-Flaming electrode puller (Sutter Instruments, Novato, CA). The tips of the patch pipettes were filled with a solution containing (in mM): $119 \mathrm{~K}-\mathrm{MeSO}, 12 \mathrm{KCl}, 1 \mathrm{MgCl}_{2}, 1$ EGTA, $0.1 \mathrm{CaCl}_{2}$, 10 HEPES, 0.4 Na-GTP, and $2 \mathrm{Mg}$-ATP, pH 7.4 (280-300 mOsm) and then back-filled with the same solution containing gramicidin $(100 \mu \mathrm{g} / \mathrm{ml})$ (Ebihara et al., 1995) yielding electrode resistances of 2-5 M 2 . Minima positive pressure was applied to the pipette while it was placed on the somatic membrane, and then slight negative pressure was used to form a seal. Only cases in which the initial seal resistance exceeded 1 G $\Omega$ were used, and all other recordings were immediately abandoned. The electrode capacitance was compensated, but the series resistance and whole-cell capacitance were not. The time course for perforation varied between individual cells, but typically, data collection commenced 15-30 min after seal formation when the series resistance $\left(R_{\mathrm{s}}\right)$ was $53 \pm 25 \mathrm{M} \Omega$ (mean \pm $\mathrm{SD} ; n=61)$. Recordings were terminated $45 \mathrm{~min}$ to $3 \mathrm{hr}$ after seal formation with a final $R_{\mathrm{s}}$ of $41 \pm 19 \mathrm{M} \Omega$ (mean $\pm \mathrm{SD} ; n=61$ ). Sudden changes in $R_{\mathrm{s}}$ were taken to indicate that the patch had ruptured, and these recordings were discarded. Data were collected using an Axopatch 200B amplifier and pClamp6 software (Axon Instruments, Foster City, CA) Current-clamp recordings were only obtained using the "fast CC" mode of the amplifier, which produces voltage recordings that are comparable with those obtained with conventional current-clamp amplifiers (Magistretti et al., 1996). Current recordings were only undertaken when $R_{\mathrm{s}}<40 \mathrm{M} \Omega$ and were restricted to measuring steady-state currents $(<100 \mathrm{pA})$ at the end of $1 \mathrm{sec}$ voltage steps (see Results). Pooled data from voltage-clamp recordings were only examined for a relatively narrow voltage region to minimize both voltage errors attributable to the $R_{\mathrm{s}}$ and space-clamp errors attributable to axial current flow (Mainen et al., 1995; White et al., 1995). Signals were filtered at 2 or $5 \mathrm{kHz}$ and digitized at 10 or $20 \mathrm{kHz}$, respectively.

Calcium imaging. All procedures were as described above, except that the whole-cell configuration was used and the patch electrodes were filled with a solution containing (in mM): $119 \mathrm{~K}-\mathrm{MeSO}_{4}, 12 \mathrm{KCl}, 1 \mathrm{MgCl}_{2}, 10$ HEPES, 0.4 Na-GTP, 2 Na-ATP, and 0.05-0.2 K-fura-2, pH 7.4 (280-300 mOsm). Electrical and optical data were collected simultaneously using a Neurodata IR283 amplifier (Cygnus Technology Inc., Delaware Water Gap, PA) and a cooled EEV37 CCD camera (Photometrics, Tucson, AZ) running in frame transfer mode. Current-clamp recordings were digitized at $10 \mathrm{kHz}$, and frame rates of $18-40 \mathrm{~Hz}$ were used for collection of optical data. Fluorescence changes were measured using an excitation wavelength of $380 \mathrm{~nm}$ and were corrected for bleaching and autofluorescence. During steady hyperpolarization, fluorescence measurements were collected, filtered at $3 \mathrm{~Hz}$, and subtracted from episodes during which the cell was depolarized or allowed to fire spontaneously to correct for bleaching. Autofluorescence was corrected by subtracting the fluorescence of a region of the slice that was devoid of fura-containing structures from the initial value of $F$. Ratiometric data were not collected, and all fluorescence measurements are therefore presented as changes in $\% \Delta F / F$. At an excitation wavelength of $380 \mathrm{~nm}$, fura-2 fluorescence decreases with increasing calcium concentration, but for the sake of clarity, the data plotted are actually $-\% \Delta F / F$ so that the decreases in fluorescence have the same polarity as increases in calcium concentration. There is a very nearly linear relationship between $\% \Delta F / F$ and calcium concentration for changes of $<50 \% \Delta F / F$ (Lev-Ram et al., 1992), and all measurements in this study were within this range.

Drugs. All drugs were obtained from Sigma (St. Louis, MO) unless otherwise noted and were applied by bath perfusion. Tetrodotoxin (TTX) $\left(\begin{array}{ll}1 & \mu \mathrm{M}\end{array}\right)$ was used to block sodium channels. The hyperpolarizationactivated cation current $\left(I_{\mathrm{h}}\right)$ was blocked with cesium $(3 \mathrm{~mm})$. Because ZD7288 (100 $\mu \mathrm{M}$; Tocris Cookson, Ballwin, MO) was found to cause significant spike broadening, it was only used to block $I_{\mathrm{b}}$ in experiment undertaken in the presence of TTX. Calcium channel blockade was achieved by either substituting cobalt $(2 \mathrm{~mm})$ for calcium in the ACSF or
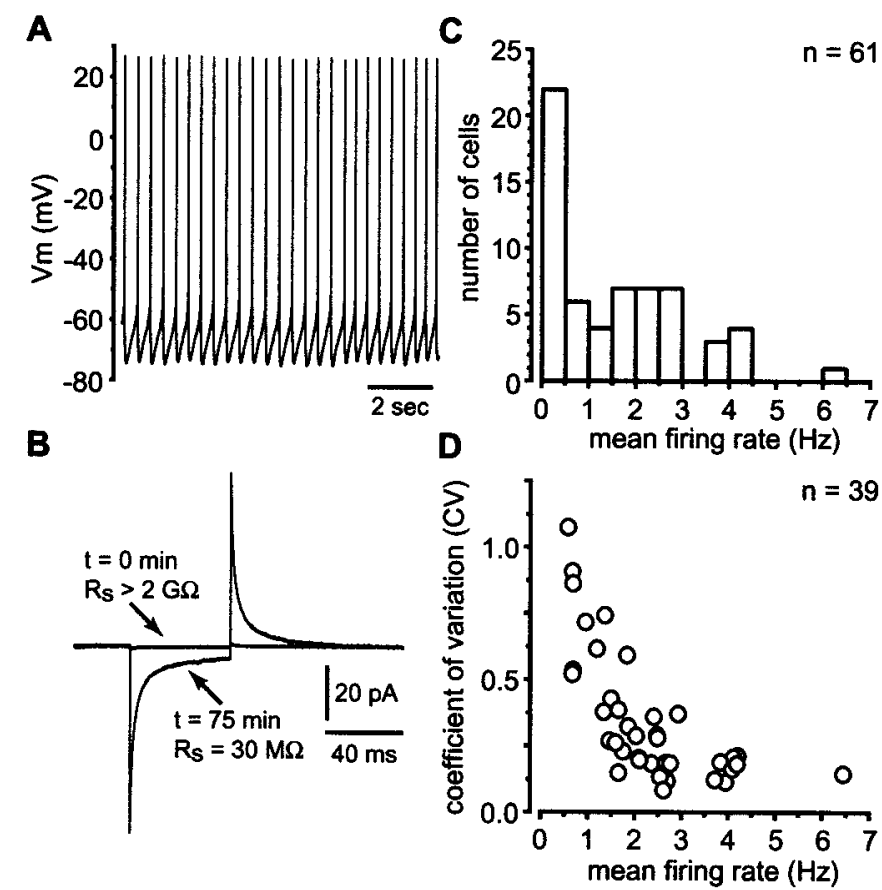

Figure 1. Firing rates and patterns of cholinergic cells. $A$, Example of a spike train recorded from a tonically active cholinergic neuron using the perforated patch configuration $45 \mathrm{~min}$ after seal formation. $B$, Averaged responses (50-100 trials) to a $2 \mathrm{mV}$ voltage step recorded immediately after seal formation and 75 min later. $C$, The firing rates of cholinergic cells were skewed toward lower values with the mean and median falling between 1 and $2 \mathrm{~Hz}$. D, A plot of the CV versus the firing rate indicates that cholinergic cells that fire more rapidly exhibit more regular spike trains.

by using cadmium $(400 \mu \mathrm{M})$. In both cases, $\mathrm{NaH}_{2} \mathrm{PO}_{4}$ was omitted from the ACSF to avoid precipitation. Cadmium and cobalt produced indistinguishable effects, and the data were therefore pooled (see Results). Bigconductance calcium-activated potassium (BK) channels were blocked using either tetraethylammonium chloride (TEA) (1 mM) or iberiotoxin $(100 \mathrm{~nm})$, which produced identical effects, and the data from the two groups were pooled (see Results). Small-conductance calcium-activated potassium (SK) channels were blocked using apamin (100 nM). Synaptic blockers were not used because neostriatal cholinergic interneurons receive minimal synaptic input in vitro, and these inputs have an undetectable effect on the spontaneous firing rates and patterns exhibited by these cells (Bennett and Wilson, 1999).

Data analysis. The firing rate was determined from a 2 min sample of spontaneous activity. The coefficient of variation (CV) (SD/mean) was calculated for all cells that exhibited a mean firing rate $\geq 0.5 \mathrm{~Hz}$. Spike threshold was defined as the point at which the first derivative of voltage with respect to time exceeded $4 V_{\mathrm{s}}^{-1}$ and corresponded to a sharp inflection in the voltage trace. The mean subthreshold voltage $\left(V_{\mathrm{m}}\right.$ mean $)$ was calculated from a 1 min sample of the voltage trace using only points negative to action potential threshold. Spike width was measured at threshold. The afterhyperpolarization (AHP) amplitude was defined as the difference in voltage between spike threshold and the peak negativity after a spike. The AHP time-to-peak was calculated as the time difference between threshold and the subsequent AHP peak. For cases in which drug treatments resulted in membrane hyperpolarization, direct-current (DC) current injection $(10-60 \mathrm{pA})$ was used to reinstate the predrug firing rate or membrane potential (in the case of quiescent neurons). The junction potential was measured directly by recording the voltage offset produced by sequentially immersing a patch electrode in the electrode solution followed by ACSF. Whole-cell recordings were corrected off-line by subtracting the measured $5 \mathrm{mV}$ potential. Comparison of corrected whole-cell data and perforated patch recordings failed to reveal a significant difference in action potential threshold (measured as described above), indicating that the junction potential was negligible in the perforated patch configuration. Statistical analyses were applied using the paired-sample $t$ test, and significance was assigned when $p<0.005$. Data are given as mean \pm SD unless otherwise stated.

\section{RESULTS}

Data analysis was restricted to cholinergic cells that exhibited a tonic single spike firing pattern or that were silent. Although cholinergic cells that displayed spontaneous bursting, defined as clustered spiking interrupted by large subthreshold voltage fluctu- 
ations (Bennett and Wilson, 1999), were also encountered, they were excluded from the present study to focus the experiments on the ionic mechanisms underlying tonic firing. The majority (46 of 61) of cholinergic cells exhibited spontaneous spiking (Fig. 1A), which persisted throughout the course of a perforated patch recording, suggesting that this technique is effectively noninvasive. Small-amplitude voltage steps $(-2 \mathrm{mV}, 50 \mathrm{msec})$ were used to assess the initial seal resistance and to periodically determine the series resistance during a recording (Fig. 1B). A range of firing rates $(1.53 \pm 1.48 \mathrm{~Hz}$; range, $0.0-6.45 \mathrm{~Hz} ; n=61)$ and patterns $(\mathrm{CV}, 0.34 \pm 0.25$; range, $0.09-1.08 ; n=39)$ were observed during perforated patch recordings (Fig. $1 C, D)$. A clear relationship between the firing rate and regularity of the spike train was seen (Fig. $1 D$ ), as has been described for the spike trains of cholinergic neurons recorded using cell-attached and extracellular recording techniques (Bennett and Wilson, 1999), providing support for the suggestion that perforated-patch recording was effectively noninvasive. The mean subthreshold membrane potential was $-62.3 \pm$ $4.0 \mathrm{mV}(n=60)$, and the action potential threshold and width were $-49.0 \pm 3.8 \mathrm{mV}(n=60)$ and $2.5 \pm 0.6 \mathrm{msec}(n=47)$, respectively. Cholinergic cells exhibited a large slow spike AHP with a peak amplitude of $18.0 \pm 4.1 \mathrm{mV}(n=41)$ and a time-to-peak of $53.1 \pm$ $13.8 \mathrm{msec}(n=38)$.

\section{Sodium}

To investigate the role of sodium influx in the generation of tonic firing, we first examined the effect of sodium channel blockade on spontaneous spiking. Application of TTX $(1 \mu \mathrm{M})$ blocked action potentials $(n=21)$ and failed to reveal any subthreshold oscillation in the membrane potential (Fig. $2 A, B$ ). The observation that action potential threshold was $-48.4 \pm 4.2 \mathrm{mV}$ before blockade of sodium channels whereas the mean membrane potential was $-59.5 \pm 6.1$ $\mathrm{mV}$ after application of TTX $(n=21)$ suggests that sodium channels are activated in the subthreshold voltage range and participate in bringing the neuron to spike threshold. To investigate this possibility, cholinergic cells in which the series resistance was $<40 \mathrm{M} \Omega$ were subjected to somatic voltage clamp. Although voltage clamp under these circumstances can produce distorted currents because of imperfect space clamp (Mainen et al., 1995; White et al., 1995), we only wanted to determine whether a sodium current was available in the subthreshold voltage range and did not attempt to investigate kinetic properties. Under control conditions, stepping from a clamp potential of -60 to $-52.5 \mathrm{mV}$ produced an inward current that persisted throughout a $1 \mathrm{sec}$ pulse (Fig. 2C). The inward current was blocked by TTX application, and repeating the same voltage step then revealed a small outward current (Fig. $2 D)$. Additionally, after TTX, a subthreshold zero current point appeared at $-60 \mathrm{mV}$ (Fig. $2 D$ ). The current-voltage (I-V) curve displayed a region of negative slope conductance between -60 and $-50 \mathrm{mV}$ that was TTX-sensitive (Fig. 2E). Furthermore, voltage steps to $-60 \mathrm{mV}$ and above evoked a net outward current in the presence of TTX $(n=9)$, indicating that whatever additional inward currents are available in this portion of the subthreshold voltage range are insufficient to drive firing in the absence of the sodium current. The control and TTX data were subtracted and pooled $(n=9)$ (Fig. $2 F)$. These data indicate that sodium channel activation occurs at potentials more positive than approximately $-60 \mathrm{mV}$, producing an inward current at subthreshold membrane potentials that assists in driving tonic firing.

In certain types of neurons, spontaneous rhythmic firing has been shown to arise from subthreshold oscillations that are action potential-independent (Llinas and Yarom, 1986; Shepard and Bunney, 1991; Kang and Kitai, 1993). Such oscillations can be revealed by applying hyperpolarizing constant current that is just sufficient to prevent action potential generation. We tested whether such subthreshold oscillations might underlie tonic firing in cholinergic cells by applying small-amplitude hyperpolarizing constant currents. A reduction in the firing rate was seen but no subthreshold oscillations were revealed (Fig. 2G-J), although the membrane potential traversed the same voltage range as it did under control

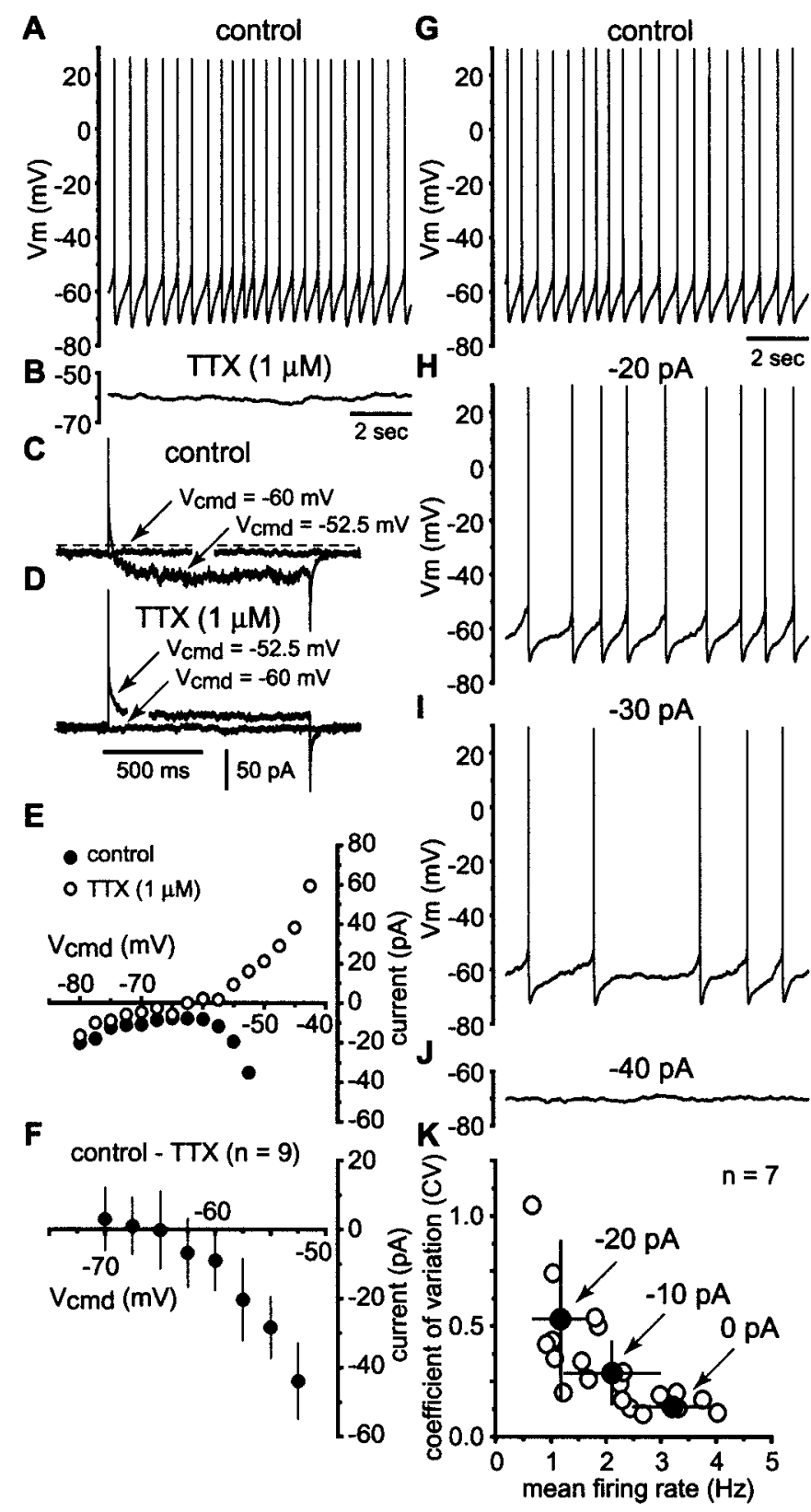

Figure 2. The role of sodium in spontaneous tonic firing. $A$, Spontaneous firing was observed in the majority of cholinergic interneurons. $B$, Application of TTX $(1 \mu \mathrm{M})$ prevented action potential generation and established a stable subthreshold membrane potential (approximately $-60 \mathrm{mV}$ ). C, Stepping the membrane from a holding potential of -60 to $-52.5 \mathrm{mV}$ elicited a slowly developing inward current that persisted throughout the pulse. The dashed line indicates the zero current point. D, After TTX (1 $\mu \mathrm{M})$ treatment, the inward current produced by the depolarizing voltage step was absent, and a small outward current was observed. Additionally, the zero current point was shifted to $-60 \mathrm{mV}$. E, The $I-V$ plot for a range of voltage steps $\left(V_{\mathrm{cmd}}\right)$ shows that, under control conditions, there is a region of negative slope conductance at potentials positive to $-60 \mathrm{mV}$ and no zero current point in the subthreshold voltage range. The inward current generated by depolarizing steps was blocked by TTX.F, Examination of the TTX-sensitive current that was obtained by subtraction for nine neurons and pooled (mean $\pm \mathrm{SD}$ ). $G-J$, Spiking rate was reduced by injection of constant negative current and failed to reveal any subthreshold oscillation in the absence of action potential generation. The firing pattern was related to firing rate, and spike trains became increasingly irregular at lower rates. $K$, For seven neurons exhibiting tonic, regular spiking $(2.45-4.03 \mathrm{~Hz}$; CV, $0.10-0.19)$, the firing rate and pattern was measured for control $(0 \mathrm{pA})$ and during steady injection of -10 and $-20 \mathrm{pA}$ (open circles). Pooled data ( filled circles; mean $\pm \mathrm{SD}$ ) confirmed that firing pattern was a function of spiking rate. 
conditions. This suggests that the rhythmic fluctuation in the membrane is not produced by an action potential-independent subthreshold oscillation. Furthermore, it was found that, as the firing rate decreased, the irregularity of the spike train increased. A group of cholinergic cells $(n=7)$, which all exhibited spontaneous regular firing (rate, 2.45-4.03 Hz; CV, 0.10-0.19) were subjected to DC hyperpolarizing current injection, and examination of the resulting spike trains confirmed that the $\mathrm{CV}$ was a function of the firing rate (Fig. $2 K$ ). These observations raise the possibility that the stochastic properties of the channels underlying the subthreshold membrane potential fluctuations during spontaneous firing contribute to the irregularity of cholinergic cell spike trains (White et al., 2000).

$I_{\mathrm{h}}$

Although the subthreshold sodium current provides an explanation for how cholinergic neurons reach action potential threshold from potentials of $-60 \mathrm{mV}$ and above, it does not account for the recovery from the AHP. This suggests that at least one other mechanism must provide a depolarizing influence at potentials more negative than $-60 \mathrm{mV}$. Because cholinergic cells possess the hyperpolarization-activated cation current, $I_{\mathrm{h}}$ (Jiang and North, 1991; Kawaguchi, 1993), and this current is known to be involved in pacemaker activity in many cell types (DiFrancesco, 1993; Maccaferri and McBain, 1996; Pape, 1996; Lüthi and McCormick, 1998b), we examined whether $I_{\mathrm{h}}$ provides a depolarizing influence in the subthreshold voltage range. Blockade of $I_{\mathrm{h}}$ with cesium (3 $\mathrm{mm})$ produced a significant reduction in firing rate $(n=9)$ (Fig. $3 A-C$, Table 1$)$ and hyperpolarized the membrane potential $(n=$ 13) (Table 1). Confirmation that cesium application blocked $I_{\mathrm{h}}$ was provided by examining the response to negative current injection. Under control conditions, there is an initial hyperpolarization followed by a sag in the membrane potential as $I_{\mathrm{h}}$ becomes activated (Fig. $3 D$ ). After cesium application, the sag is absent, indicating that $I_{\mathrm{h}}$ is blocked (Fig. $3 D$ ). Using somatic voltage clamp, we found that cesium application reduced a slowly developing hyperpolarization-activated inward current and produced a shift in the holding current at a clamp potential of $-60 \mathrm{mV}$ (Fig. $3 E, F$ ). Examination of the $I-V$ curve under control conditions and after cesium treatment shows that blocking $I_{\mathrm{h}}$ established a zero current point at approximately $-65 \mathrm{mV}$ in this neuron (Fig. $3 G$ ). Subtraction of the cesium-sensitive current was used to allow examination of pooled data $(n=5)$, which revealed that $I_{\mathrm{h}}$ is activated and provides an inward current throughout the subthreshold voltage range observed in cholinergic cells (Fig. $3 H$ ). The h-current between -65 and $-55 \mathrm{mV}$ is relatively small, which is consistent with this voltage range being at the foot of the activation curve for $I_{\mathrm{h}}$ (Hagiwara and Irisawa 1989; Lüthi and McCormick 1998a, 1999). Because the voltage range over which $I_{\mathrm{h}}$ and the subthreshold sodium current overlap, the most likely explanation for spontaneous firing in cholinergic interneurons is that these two currents together ensure that there is no zero current point at any subthreshold membrane potential. Although $I_{\mathrm{h}}$ is critical in the subthreshold voltage range, examination of frequency-current $(f-I)$ and instantaneous $f-I$ plots revealed that the h-current did not contribute significantly to the suprathreshold properties of cholinergic cells (data not shown; $n=9$ ).

\section{Calcium imaging}

To investigate the role of calcium in tonic firing, we first used imaging to determine whether fluctuations in calcium levels were detectable in cholinergic cells. Conventional whole-cell recording methods were used for this part of the study, and the neurons were loaded with the calcium indicator fura-2 (50-200 $\mu \mathrm{M})$ to examine the intracellular calcium dynamics. In response to small-amplitude (20-80 pA) depolarizing current injections (1-5 sec), cholinergic cells generated trains of spikes with each spike associated with an elevation in intracellular calcium $(n=28)$, which was detectable in both somatic and dendritic compartments (Fig. 4A,B). Hyperpolarization from subthreshold membrane potentials $(-50$ to -80

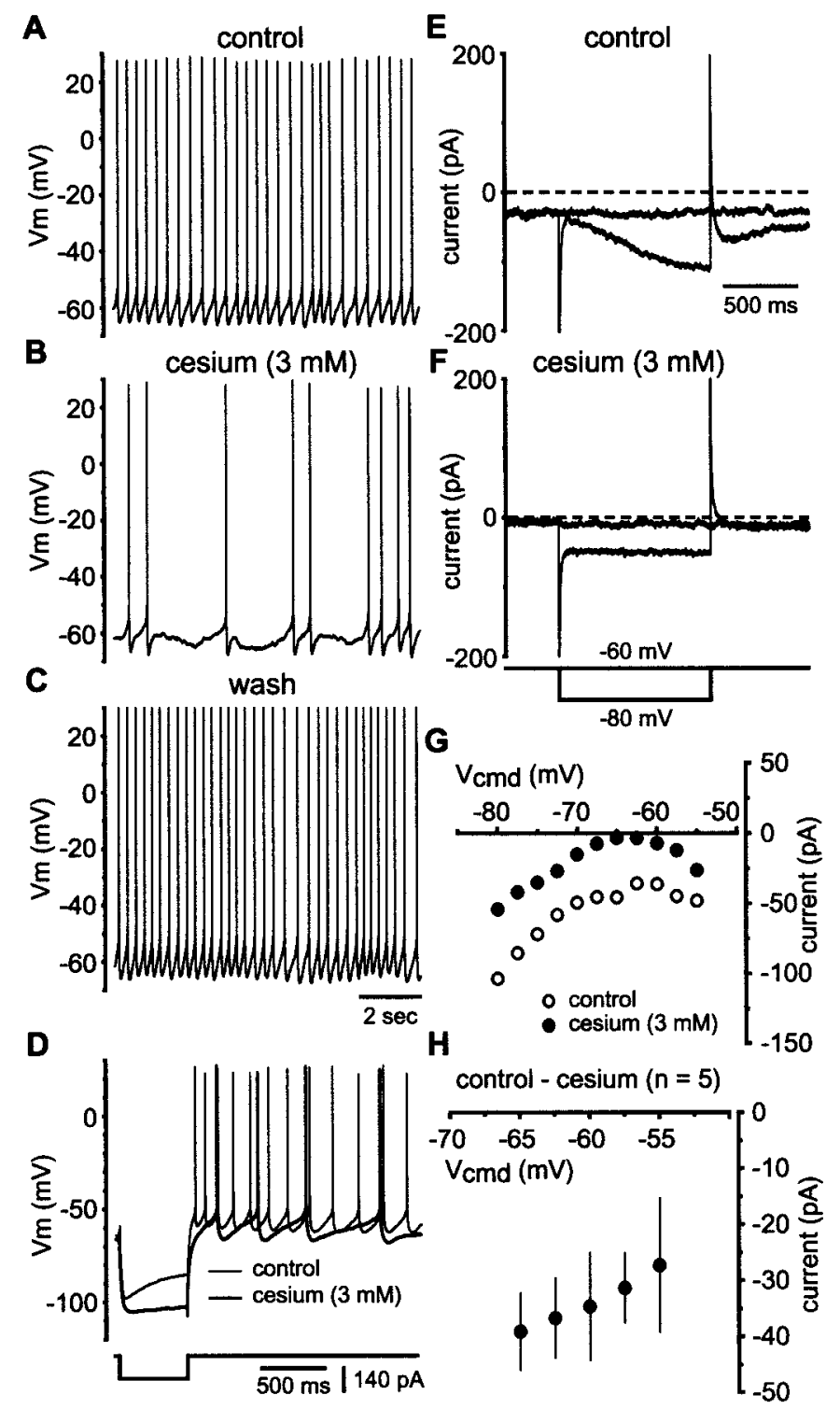

Figure 3. $\quad I_{\mathrm{h}}$ is required for spontaneous firing. $A$, Tonic firing observed under control conditions. $B$, Application of cesium $(3 \mathrm{mM})$ produced a profound decrease in the firing rate and an accompanying increase in the irregularity of the spike train. $C$, After washout of cesium, the firing rate and pattern were restored to control values. $D$, Injection of negative current produced an initial hyperpolarization followed by a sag in the membrane potential caused by activation of $I_{\mathrm{h}}$. Cesium abolished the sag, confirming that $I_{\mathrm{h}}$ was blocked. $E$, Stepping from a holding potential of -60 to $-80 \mathrm{mV}$ evoked a slowly developing inward current. $F$, Application of cesium reduced the amplitude of the inward current measured at the end of the pulse and shifted the zero current point. $G$, The $I-V$ plot for a range of voltage steps $\left(V_{\mathrm{cmd}}\right)$ from a holding potential of $-60 \mathrm{mV}$ reveals that cesium blocks an inward current that is activated throughout the subthreshold voltage range. Cesium also established a zero current point at approximately -65 $\mathrm{mV}$ in this neuron. $H$, The cesium-sensitive current was obtained by subtraction $(n=5)$ and exhibited the voltage dependence expected for $I_{\mathrm{h}}$.

$\mathrm{mV} ; n=10$ ) failed to produce any detectable reduction in intracellular calcium (Fig. 4C), suggesting that calcium entry was primarily spike-triggered. Furthermore, the rebound in the membrane potential that followed hyperpolarization also failed to generate a detectable elevation in calcium level (Fig. 4C). However, there remains the possibility that a T-type calcium current was contributing to the rebound but produced an insufficient elevation in the proximal intracellular calcium concentration to be detected optically. We therefore examined the rebound after hyperpolarizing current injection (500 msec, $-200 \mathrm{pA}$ ) in nine neurons under control conditions and after the application of TTX $(1 \mu \mathrm{M})$ and cesium ( $3 \mathrm{~mm} ; n=4)$ or ZD7288 $(100 \mu \mathrm{M} ; n=5)$ to block $I_{\mathrm{h}}$. 
Table 1. Effects of blocking $I_{h}$, calcium, BK, or SK channels

\begin{tabular}{|c|c|c|c|c|c|c|c|}
\hline & $\begin{array}{l}\text { Firing rate } \\
(\mathrm{Hz})\end{array}$ & $\begin{array}{l}\text { Coefficient } \\
\text { of variation } \\
(\mathrm{CV})\end{array}$ & $V_{\mathrm{m}}$ mean $(\mathrm{mV})$ & $\begin{array}{l}\text { Spike thresh- } \\
\text { old }(\mathrm{mV})\end{array}$ & $\begin{array}{l}\text { Spike width } \\
\text { (msec) }\end{array}$ & $\begin{array}{l}\text { AHP ampli- } \\
\text { tude }(\mathrm{mV})\end{array}$ & $\begin{array}{l}\text { AHP time-to- } \\
\text { peak (msec) }\end{array}$ \\
\hline Control & $1.99 \pm 1.11$ & $0.19 \pm 0.10$ & $-63.9 \pm 3.7$ & $-50.1 \pm 3.3$ & $2.4 \pm 0.2$ & $18.4 \pm 3.3$ & $60.5 \pm 12.3$ \\
\hline Cesium & $\begin{array}{l}0.61 \pm 1.05 \\
(n=9)^{*}\end{array}$ & $\begin{array}{l}0.87 \pm 0.58 \\
(n=5)\end{array}$ & $\begin{array}{l}-69.9 \pm 7.2 \\
(n=13)^{*}\end{array}$ & $\begin{array}{l}-48.6 \pm 3.3 \\
(n=10)\end{array}$ & $\begin{array}{l}2.4 \pm 0.3 \\
(n=10)\end{array}$ & $\begin{array}{l}18.3 \pm 4.2 \\
(n=10)\end{array}$ & $\begin{array}{l}60.0 \pm 10.8 \\
(n=10)\end{array}$ \\
\hline $\begin{array}{l}\text { Control } \\
\text { Cadmium } \\
\quad \text { or }\end{array}$ & $1.52 \pm 1.30$ & $0.21 \pm 0.11$ & $-62.6 \pm 3.4$ & $-49.8 \pm 3.0$ & $2.2 \pm 0.4$ & $19.2 \pm 2.5$ & $54.6 \pm 14.9$ \\
\hline cobalt & $\begin{array}{l}0.29 \pm 0.61 \\
(n=14 ; 7,7)^{*}\end{array}$ & $\begin{array}{l}1.88 \pm 0.88 \\
(n=4 ; 4,0)\end{array}$ & $\begin{array}{l}-66.6 \pm 4.5 \\
(n=20 ; 13,7)^{*}\end{array}$ & $\begin{array}{l}-47.5 \pm 3.2 \\
(n=16 ; 9,7)^{*}\end{array}$ & $\begin{array}{l}1.3 \pm 0.2 \\
(n=16 ; 9,7)^{*}\end{array}$ & $\begin{array}{l}10.2 \pm 3.3 \\
(n=16 ; 9,7)^{*}\end{array}$ & $\begin{array}{l}2.4 \pm 1.0 \\
(n=15 ; 9,6)^{*}\end{array}$ \\
\hline $\begin{array}{l}\text { Control } \\
\text { TEA or }\end{array}$ & $3.47 \pm 2.18$ & $0.24 \pm 0.12$ & $-63.6 \pm 3.5$ & $-50.2 \pm 2.3$ & $2.1 \pm 0.2$ & $18.3 \pm 5.6$ & $48.5 \pm 16.3$ \\
\hline IBTX & $\begin{array}{l}4.53 \pm 3.08 \\
(n=4 ; 3,1)\end{array}$ & $\begin{array}{l}0.35 \pm 0.26 \\
(n=4 ; 3,1)\end{array}$ & $\begin{array}{l}-62.3 \pm 3.8 \\
(n=7 ; 5,2)\end{array}$ & $\begin{array}{l}-49.1 \pm 2.8 \\
(n=7 ; 5,2)\end{array}$ & $\begin{array}{l}2.7 \pm 0.4 \\
(n=7 ; 5,2)^{*}\end{array}$ & $\begin{array}{l}16.8 \pm 5.7 \\
(n=7 ; 5,2)\end{array}$ & $\begin{array}{l}44.0 \pm 17.4 \\
(n=7 ; 5,2)\end{array}$ \\
\hline Control & $2.33 \pm 1.69$ & $0.29 \pm 0.15$ & $-58.7 \pm 4.7$ & $-49.1 \pm 3.3$ & $3.0 \pm 0.4$ & $15.6 \pm 4.6$ & $51.9 \pm 13.0$ \\
\hline Apamin & $\begin{array}{l}2.04 \pm 0.88 \\
(n=7)\end{array}$ & $\begin{array}{l}0.84 \pm 0.33 \\
(n=5)\end{array}$ & $\begin{array}{l}-57.0 \pm 4.6 \\
(n=9)\end{array}$ & $\begin{array}{l}-47.4 \pm 4.3 \\
(n=6)\end{array}$ & $\begin{array}{l}3.4 \pm 0.5 \\
(n=6)^{*}\end{array}$ & $\begin{array}{l}7.9 \pm 2.7 \\
(n=6)^{*}\end{array}$ & $\begin{array}{l}28.3 \pm 22.9 \\
(n=4)\end{array}$ \\
\hline
\end{tabular}

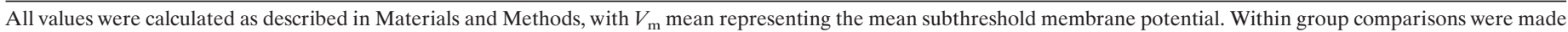

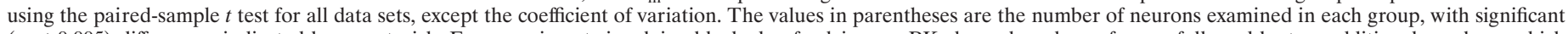

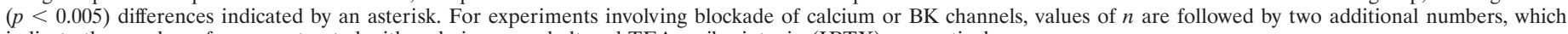
indicate the number of neurons treated with cadmium or cobalt and TEA or iberiotoxin (IBTX), respectively.

Blockade of sodium channels reduced the amplitude of the rebound, indicating that a sodium current contributed to bringing the neuron to threshold (Fig. 4D). After blockade of $I_{\mathrm{h}}$, no timedependent sag in the membrane potential was observed in response to the hyperpolarizing current pulse and the rebound was completely absent (Fig. $4 E$ ). Identical observations were made for nine neurons and indicate that, if a T-type calcium current is present, it is of insufficient magnitude to account for the rebound. These data also suggest that a T-current is unlikely to play a significant role in the depolarizing ramp to spike threshold during spontaneous tonic firing.

Spontaneous firing was also observed in fura-loaded cholinergic cells, albeit less frequently than with perforated patch recording because of the previously described effects of intracellular dialysis (Bennett and Wilson, 1999). In neurons that continued to fire spontaneously $(n=10)$, the spike-associated elevations in intracellular calcium were very similar to those produced by current injection (Fig. $5 A, B$ ). The relationship between the membrane potential and the time at which calcium elevations were observed was determined by examining data collected during spontaneous firing after the neuron had reached steady state. Using the maximal available temporal resolution, it was found that very little elevation in calcium occurred during the depolarizing ramp to spike threshold and that increases in the intracellular calcium concentration were primarily spike-triggered $(n=10)$ (Fig. $5 C)$. Because sodium channel blockade established a resting membrane potential that was $\sim 11$ $\mathrm{mV}$ below action potential threshold and no net inward current was evoked by voltage steps to $-60 \mathrm{mV}$ and above in the presence of TTX (see above), we propose that subthreshold calcium entry plays a minor role in driving tonic firing.

\section{Calcium}

The role of calcium in spontaneous tonic firing was investigated by blocking calcium channels by either substituting equimolar cobalt $(2 \mathrm{mM})$ for calcium or adding cadmium $(400 \mu \mathrm{M})$ to the ACSF. Cobalt or cadmium treatment silenced the majority (10 of 14) neurons tested and resulted in the emergence of burst firing in the remaining four cells (Fig. $6 A, B$ ). In the other 10 cholinergic neurons, steady depolarizing current (10-60 pA) was used to reinstate spiking and elicited clustered or burst firing (data not shown). Measurement of the mean subthreshold membrane potential revealed that calcium channel blockade produced a significant hyper- polarization of the membrane potential $(n=20)$ (Table 1). This was somewhat surprising in light of the fact that the imaging data, voltage-clamp recordings, and the current-clamp investigation of the rebound response all suggest that subthreshold calcium currents are insufficient to drive cholinergic neurons to spike threshold. The observation that depolarizing current restored spiking suggested that preventing calcium entry had reduced the availability of a subthreshold inward current. A possible explanation is that blocking calcium channels produces a hyperpolarizing shift in voltage range of activation of $I_{\mathrm{h}}$ by reducing the intracellular calcium concentration (Hagiwara and Irisawa, 1989; Lüthi and McCormick, 1998a) or via calcium-dependent regulation of intracellular cAMP (DiFrancesco and Tortora, 1991; DiFrancesco and Mangoni, 1994; Lüthi and McCormick, 1999). Using somatic voltage clamp, we found that application of cadmium or cobalt caused a reduction in the current that was elicited with hyperpolarizing voltage steps (Fig. $6 C, D$ ). The $I-V$ curve generated before and after calcium channel blockade (Fig. 6E) shows that cadmium reduced an inward current that was available throughout the subthreshold voltage range. The current blocked by cadmium or cobalt was obtained by subtraction, and the data were pooled $(n=5)$. A large cell to cell variability was observed, which is apparent from the SD (Fig. $6 F$ ), and although a clear voltage-dependence was not observed, the subtracted current was similar to the h-current in that it was activated throughout the subthreshold voltage range (compare Figs. $3 H, 6 F)$. We therefore propose that the hyperpolarization that occurs as a consequence of blocking calcium channels arises primarily from a reduction in the availability of $I_{\mathrm{h}}$, which is produced by a direct or indirect calcium-dependent hyperpolarizing shift in the voltage range of activation of this current. However, we cannot rule out the possibility that the hyperpolarization produced by calcium channel blockade might also be contributed to by reduction of a subthreshold calcium current.

In addition to causing hyperpolarization, blockade of calcium channels also produced profound alterations in the spiking properties of cholinergic cells. Under control conditions, the action potential waveform exhibits a shoulder during the repolarizing phase (Fig. 6G) (see Fig. 8B). After calcium channel blockade spike width was significantly reduced $(n=16)$ (Table 1$)$ and the shoulder was no longer visible (Fig. $6 G$ ), indicating that calcium influx contributes to the time course and shape of the action 


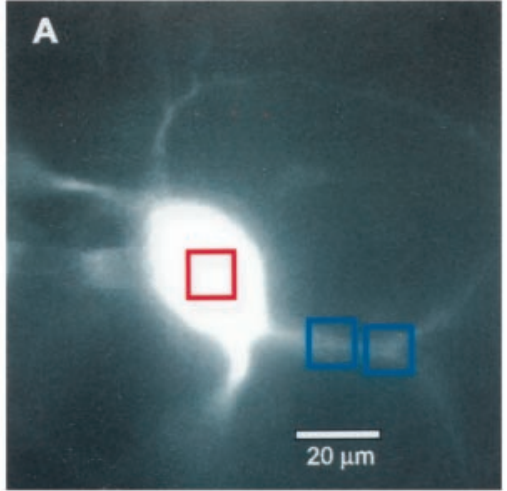

B

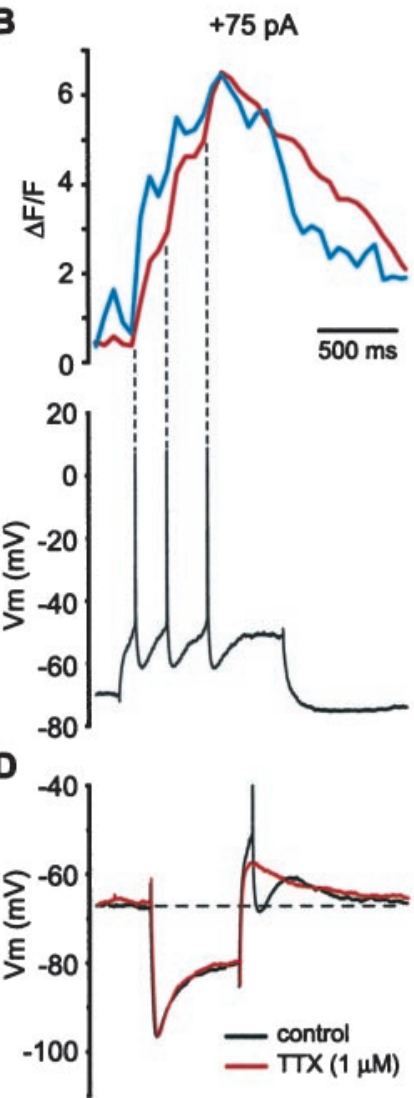

C
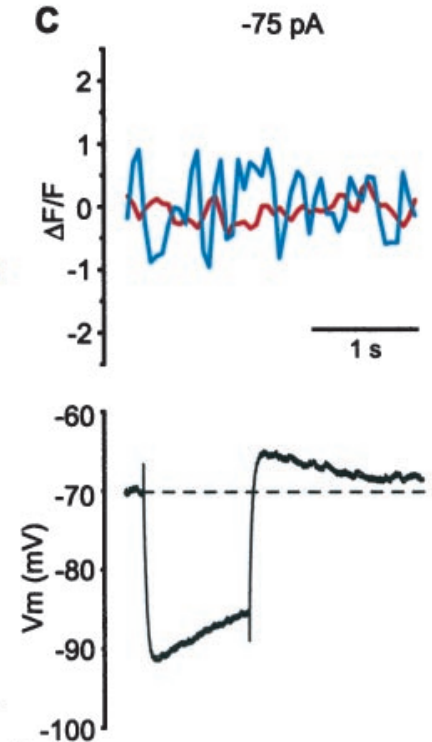

E

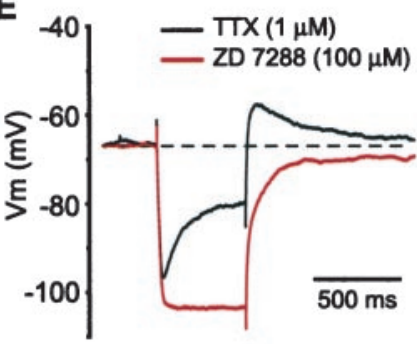

Figure 4. Voltage dependence of calcium influx. $A$, Fura-2-loaded cholinergic neuron at an excitation wavelength of $380 \mathrm{~nm}$. The red box over the soma and the blue boxes over the dendrites are the areas from which the fluorescence signals were measured. $B$, Examination of the response to current injection $(+75 \mathrm{pA})$ revealed that each spike was associated with a calcium elevation in both the soma and dendrites. $C$, Injection of negative current $(-75 \mathrm{pA})$ produced a hyperpolarization and a subsequent sag in the membrane potential attributable to activation of $I_{\mathrm{h}}$. After termination of the current pulse, a rebound in the membrane potential was observed. There was no detectable alteration in the fluorescence signal either in response to the hyperpolarization or the rebound. Calcium signals illustrated $B$ and $C$ are individual sweeps. $D$, Under control conditions, injection of negative current $(-200 \mathrm{pA})$ produced a hyperpolarization and a subsequent sag in the membrane potential, which was followed by a rebound in the membrane potential after termination of the pulse. Application of TTX $(1 \mu \mathrm{M})$ reduced the amplitude the rebound. $E$, Blockade of $I_{\mathrm{h}}$ eliminated the sag during membrane hyperpolarization and abolished the rebound.

potential waveform. Examination of the AHP before and after calcium channel blockade illustrates that the slow AHP that normally follows individual spikes is calcium-dependent because it is almost completely absent when calcium channels are blocked (Fig. $6 H$, Table 1) (Kawaguchi, 1992). The single-spike AHP, which typically lasts a few hundred milliseconds, is one of the determi-

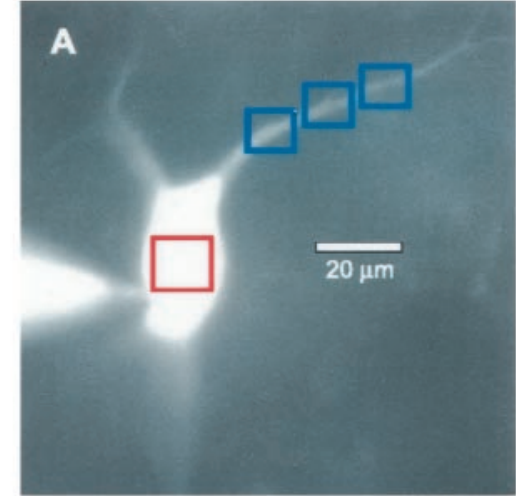

B
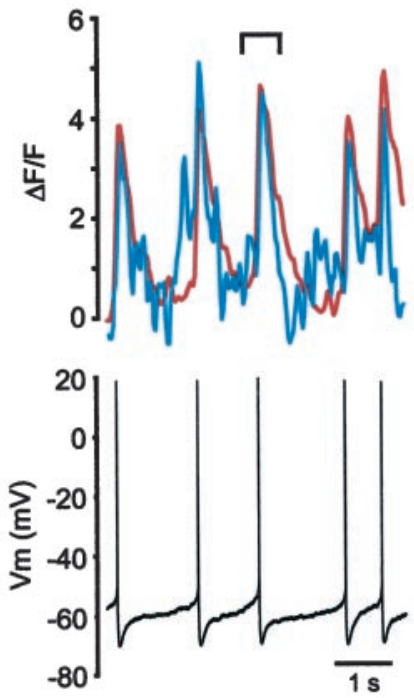

C

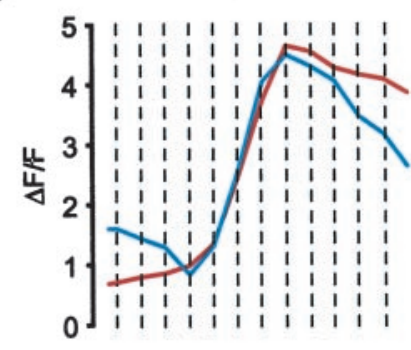

Figure 5. Calcium dynamics during spontaneous firing. $A$, Fluorescence image (380 $\mathrm{nm}$ excitation) of a cholinergic neuron loaded with fura- 2 during conventional whole-cell recording. The colored boxes are the locations from which the fluorescence measurements were obtained. $B$, Simultaneous fluorescence and electrical measurements during spontaneous firing revealed concurrent spike-triggered elevations in calcium concentration in the soma and primary dendrite (bracket indicates data shown in $C$ ). $C$, Examination of a single spike and the associated calcium transient during spontaneous firing confirms that elevations in intracellular calcium are primarily spike-triggered with minimal calcium influx occurring during the depolarizing ramp to action potential threshold. The dashed lines demarcate the individual frames $(30 \mathrm{msec})$ for the fluorescence data. Calcium signals illustrated $B$ and $C$ are individual sweeps.

nants of the interspike interval and reducing calcium influx, and therefore the amplitude of the AHP might be expected to alter the response of cholinergic cells to depolarizing input. Examination of firing elicited by positive current injection confirmed that calcium plays a crucial role in regulating spike timing. Under control conditions, small-amplitude (20-140 pA) depolarizing current injections produced regular spike trains that exhibited some adaptation at higher firing rates (Fig. 7A) (Kawaguchi, 1992). After calcium channel blockade with cadmium or cobalt, cholinergic neurons fired many more spikes in response to a given current pulse (Fig. $7 B$ ), which resulted in a profound increase in the slope of the $f-I$ relationship and a several-fold increase in the instantaneous $f-I$ relationship (Fig. $7 C$ ). The effects of cadmium and cobalt were indistinguishable, and the data were therefore pooled $(n=$ 13) and provided confirmation that calcium is critical for regulating the interspike interval (Fig. $7 C, D$ ). Examination of the instantaneous $f-I$ plots shows that, after the blockade of calcium channels, there is considerable spike frequency adaptation during highfrequency firing (Fig. 7C,D). Additionally, there is a large, persistent hyperpolarization that lasts for $>1 \mathrm{sec}$ after the episode of 


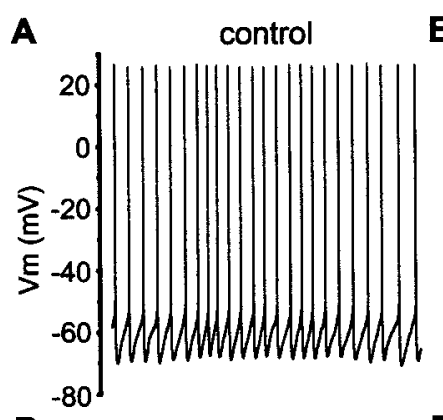

E
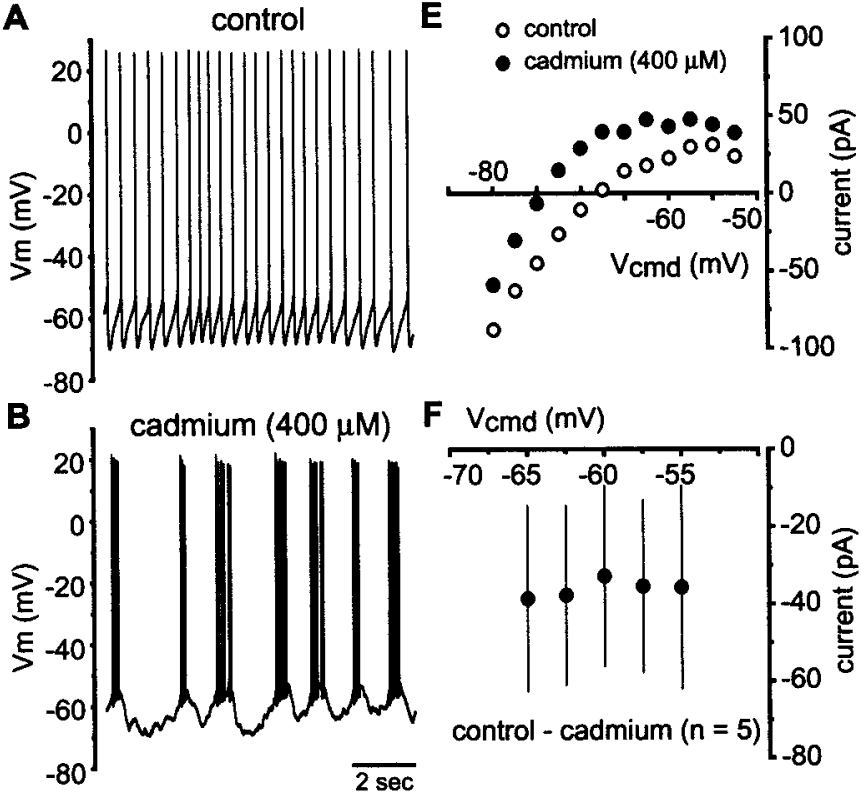

F $\mathrm{V}_{\mathrm{cmd}}(\mathrm{mV})$
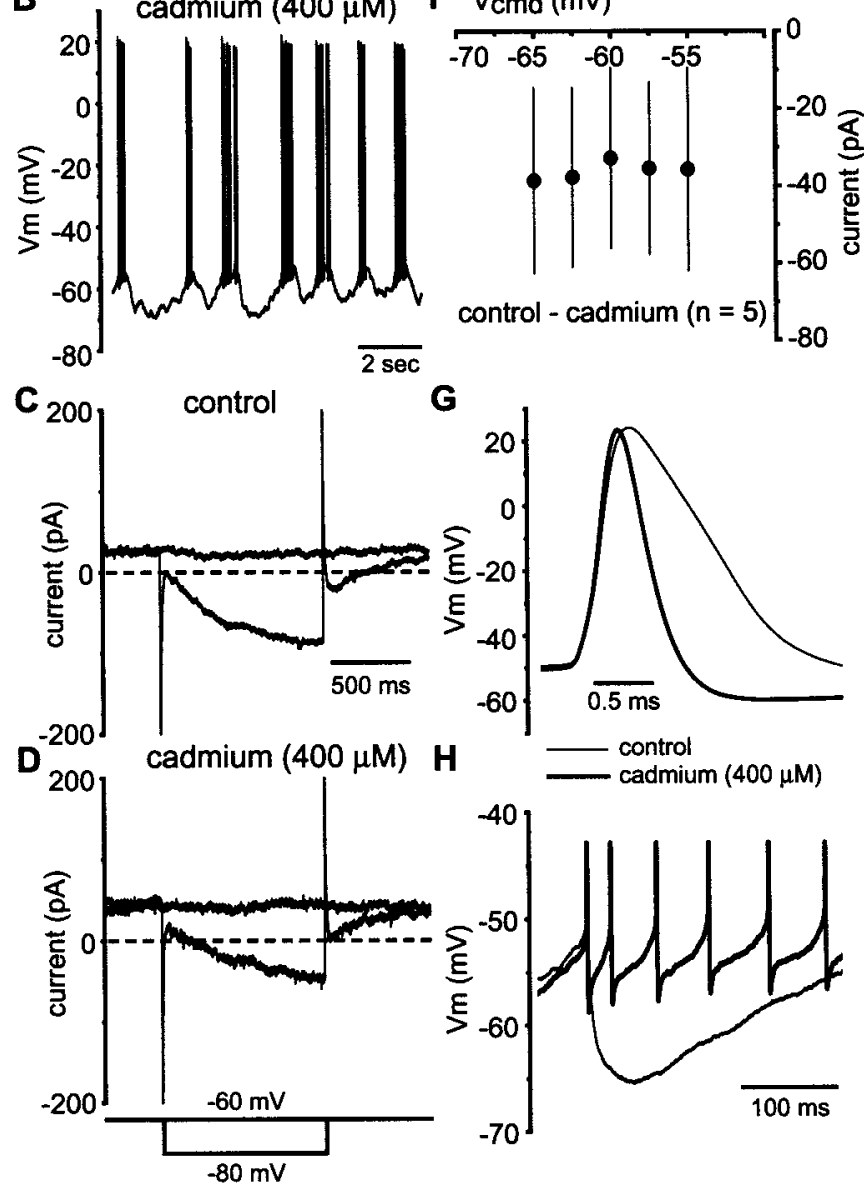

Figure 6. Calcium is critical for tonic firing. $A$, Spontaneous tonic firing. $B$, Application of cadmium $(400 \mu \mathrm{M})$ converted tonic spiking to rhythmic bursting, during which clusters of spikes were generated in rapid succession and separated by slow subthreshold oscillations in the membrane potential. $C$, Stepping from a holding potential of -60 to $-80 \mathrm{mV}$ activated the slowly developing h-current. $D$, After calcium channel blockade, the same voltage step produced a smaller current and was accompanied by a shift in the holding current at $-60 \mathrm{mV}$. $E$, The $I-V$ plot for this neuron generated using a range of voltage steps $\left(V_{\mathrm{cmd}}\right)$ indicates that there has been a reduction in a subthreshold inward current. $F$, The current that was reduced by calcium channel blockade was obtained by subtraction and pooled $(n=5$; symbols indicate mean $\pm \mathrm{SD}$ ) $G$, Under control conditions, cholinergic neurons generate relatively broad spikes that exhibit a shoulder on the falling phase. Calcium channel blockade produced a pronounced narrowing of the spike and abolished the shoulder. $H$, Application of cadmium abolished the slow AHP that normally follows individual spikes.

firing (Fig. $7 B$ ), raising the possibility that both adaptation and the hyperpolarization result from activation of a voltage-dependent outward current that accumulates during the spike train. Cholinergic neurons are known to possess a slowly activating voltagedependent potassium current that could underlie these phenomena (Song et al., 1998).
A

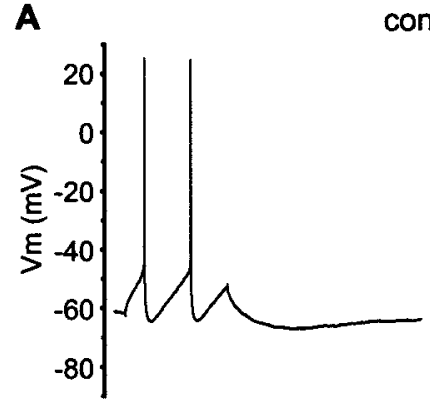

control

B
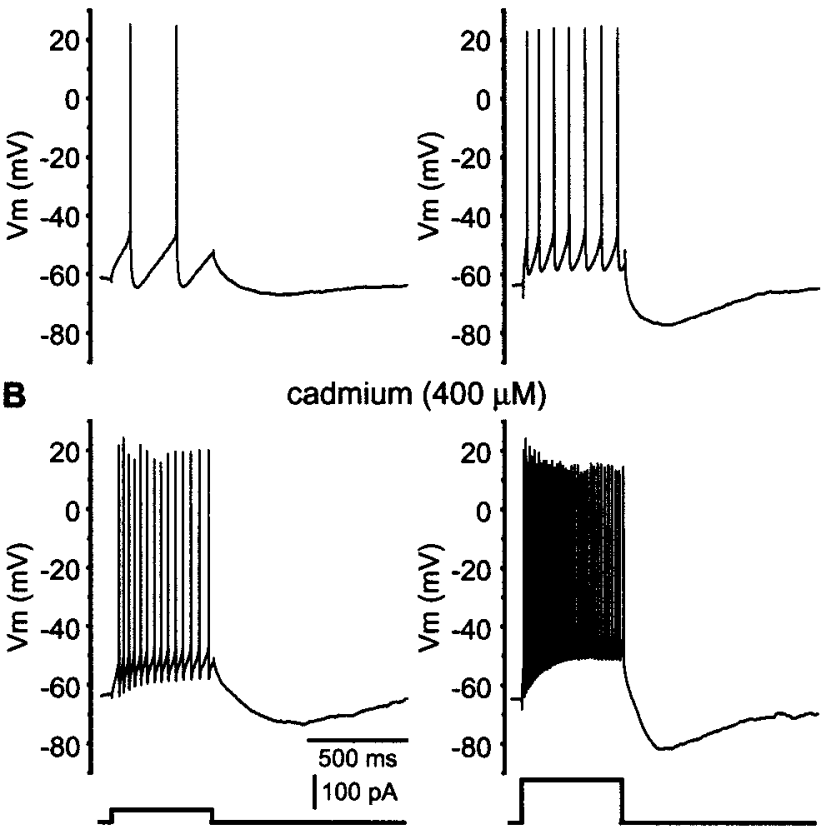

C
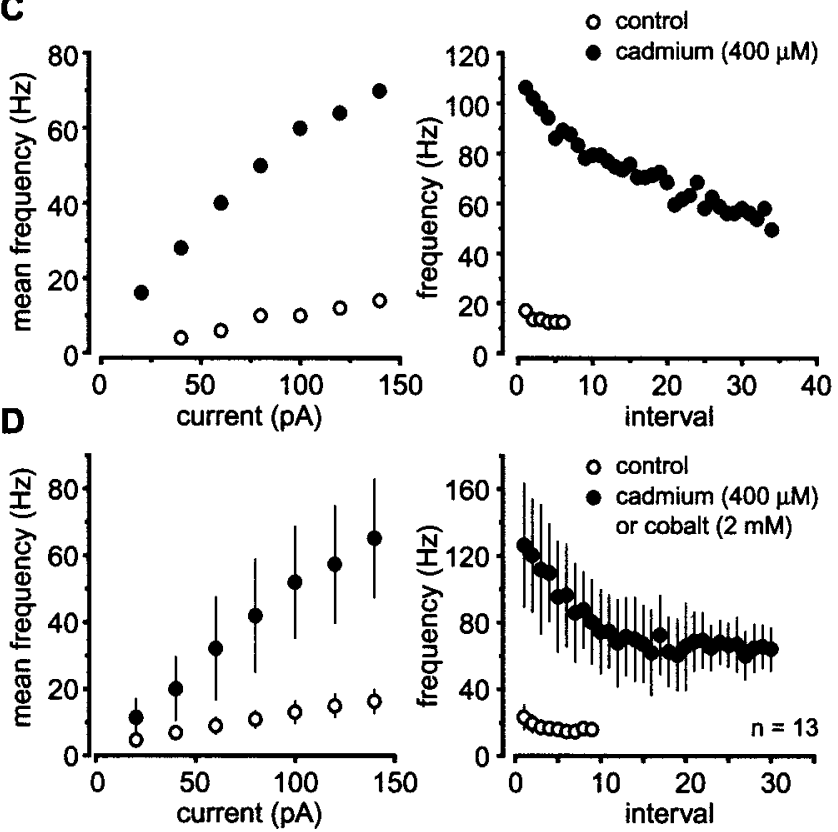

Figure 7. Calcium regulates the firing properties of cholinergic neurons. $A$ In response to depolarizing current injection $(+40 \mathrm{pA}$; left $)$, cholinergic cells generated spikes that were separated by a slow AHP. Injection of larger amplitude currents $(+140 \mathrm{pA}$; right $)$ evoked repetitive spiking with minimal spike frequency adaptation. $B$, After application of cadmium (400 $\mu \mathrm{M})$, the same cell generates many more spikes in response to a given current injection and spike-frequency adaptation. $C$, Calcium channel blockade produces a profound increase in the slope of the $f-I$ relationship (left $)$. The instantaneous $f-I$ plot $(+140 \mathrm{pA}$; right $)$ shows a pronounced increase in the initial firing rate and substantial spike frequency adaptation after blockade of calcium channels. $D$, Pooled data $(n=13,9$ cadmium, 4 cobalt; symbols indicate mean \pm SD) confirm that calcium channel blockade profoundly alters both the $f-I$ and instantaneous $f-I$ relationships.

\section{Calcium: BK plus SK channels}

Because calcium influx was clearly involved in shaping the action potential waveform and in the generation of the AHP, we investigated whether calcium-activated potassium currents might contribute to spike repolarization and determined the identity of the current underlying the AHP. BK channels are involved in the repolarization process in many cell types. BK channels are readily 
A

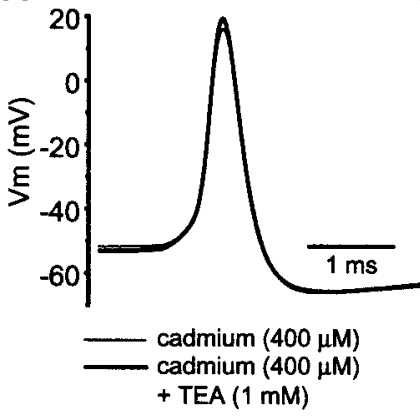

B

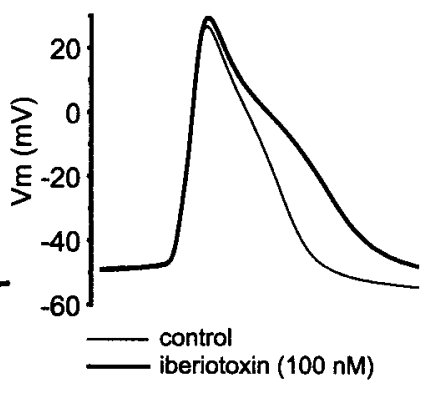

Figure 8. Spike-triggered calcium entry activates BK channels, which contribute to repolarization. $A$, Application of TEA $(1 \mathrm{mM})$ after cadmium treatment had no discernable effect on action potential width. $B$, In the presence of calcium-containing ACSF, spike width was significantly broadened after treatment with TEA or iberiotoxin (100 nM).

blocked by low concentrations of TEA, but there are several types of voltage-dependent potassium channel, including the Kv3 family of currents, Kv1.1, and KCNQ2 (Coetzee et al., 1999; Rudy et al., 1999), which are also blocked by low concentrations of TEA. We first determined whether TEA $(1 \mathrm{~mm})$ had any effects on the spike waveform after first blocking calcium channels with cadmium or cobalt. In the presence of calcium channel blockers, application of TEA was without effect $(n=4)$ and produced no detectable alteration in spike width or threshold (Fig. $8 A$ ), indicating that voltage-dependent potassium channels sensitive to low-dose TEA do not play an important role in spike repolarization in cholinergic cells. However, when calcium influx was not attenuated, addition of TEA ( $1 \mathrm{~mm} ; n=5)$ produced significant spike broadening (Table 1). This effect was mimicked by application of iberiotoxin $(100 \mathrm{nM}$; $n=2$ ) (Fig. $8 B$ ), indicating that spike-triggered elevations of intracellular calcium activate BK channels, which then contribute to spike repolarization.

The AHP that follows individual spikes in cholinergic cells is almost completely lost after cadmium or cobalt treatment (Fig. $6 E$ ), suggesting the involvement of a calcium-mediated process. This was confirmed using apamin $(100 \mathrm{nM} ; n=6)$, which blocks a class of SK calcium-activated potassium channels. The most obvious effect of blocking SK channels was that spontaneous tonic firing was converted to rhythmic bursting (Fig. 9A,B). Bursting was characterized by spike clusters separated by large-amplitude oscillations of the membrane potential. The amplitude of the AHP after individual spikes within a burst was significantly reduced (Fig. 9C) and the spike was significantly broadened (Table 1). Although SK channels are not thought to be involved in spike repolarization directly, apamin might cause spike broadening by blocking any SK channels that are open at subthreshold voltages. The response to current injection was altered after apamin treatment (Fig. 9D,E), and the instantaneous firing rate was found to be elevated at the beginning of the spike train (Fig. $9 F$ ). There was rapid adaptation, and frequently firing ceased before termination of the current injection, which was followed by a long-duration hyperpolarization. Spike cessation likely resulted from accumulation of a voltageactivated outward current and perhaps the activation of an apamininsensitive calcium-activated potassium current.

\section{DISCUSSION}

Spontaneous tonic firing in neostriatal cholinergic interneurons is generated by the intrinsic membrane properties, which ensure that there is no zero current point in the subthreshold voltage range and therefore no resting membrane potential. Thus, endogenous excitability is central to spike timing in cholinergic cells. The spontaneous firing rates and patterns observed in this study indicate that the intrinsic membrane properties are probably primarily responsible for the generation of the ongoing spike sequences, which are characteristic of TANs recorded in vivo.
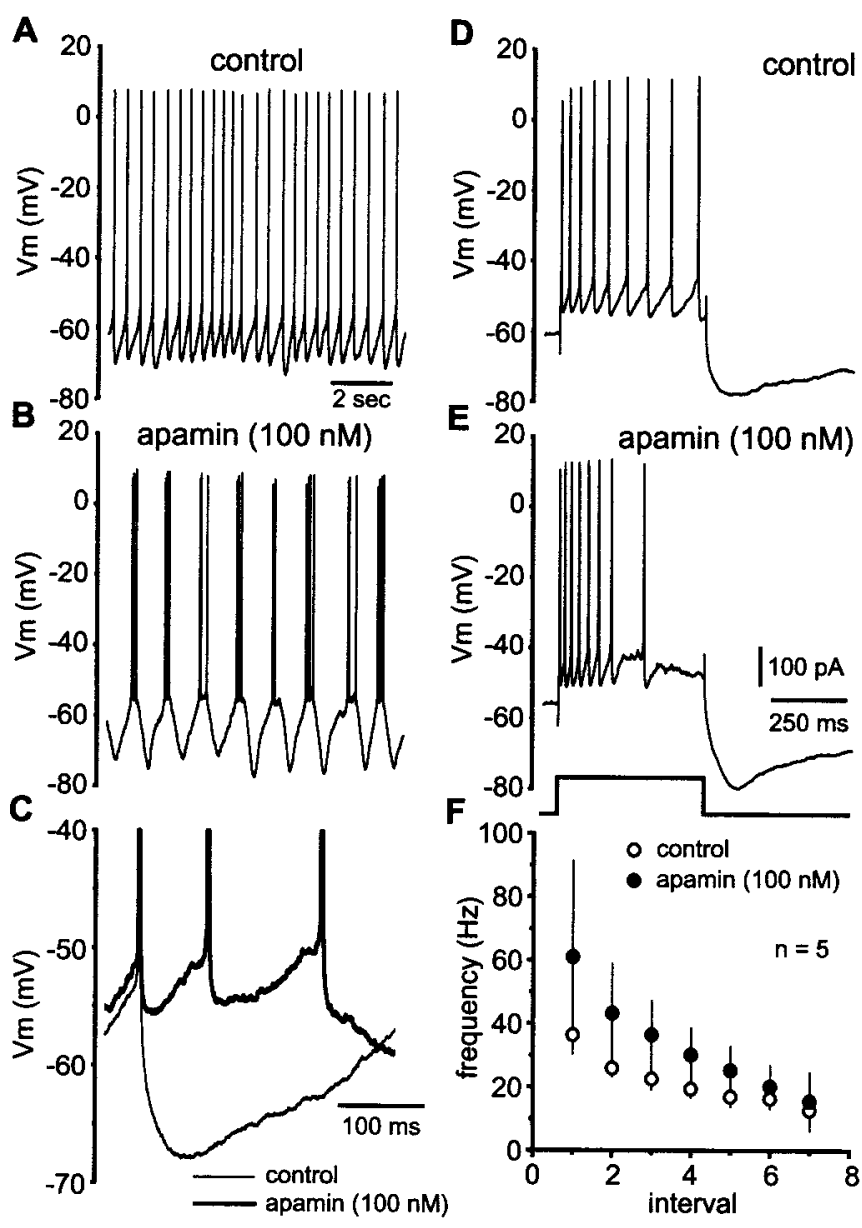

Figure 9. Calcium-activated SK channels underlie the AHP and regulate spike patterning. $A$, Under control conditions, spontaneous tonic firing was observed. $B$, Application of apamin (100 nM), which blocks calciumdependent SK channels, converted tonic firing to rhythmic bursting. $C$, The AHP after individual spikes was completely blocked by apamin, but between bursts, there was a large slow hyperpolarization. $D$, Injection of depolarizing current elicited a train of spikes that displayed spike frequency adaptation. E, After application of apamin, the same current pulse evoked spiking with a higher initial firing rate but with much more pronounced adaptation and resulted in spike cessation before termination of the current pulse. $F$, Apamin produced an elevation in the instantaneous firing rate and more pronounced spike-frequency adaptation $(n=5$; symbols indicate mean $\pm \mathrm{SD})$.

\section{Sodium and $I_{\mathrm{h}}$ drive spiking}

The combined depolarizing action of a subthreshold sodium current and $I_{\mathrm{h}}$ drive cholinergic cells to spike threshold. The voltage range over which these two currents are activated overlap, producing an inward current at all subthreshold membrane potentials. Blockade of sodium channels with TTX established a stable resting membrane potential, which was $\sim 10 \mathrm{mV}$ negative to spike threshold, indicating that the sodium current is required to bring cholinergic cells to a voltage at which spikes can be initiated. Somatic voltage clamp revealed the presence of a TTX-sensitive inward current that was activated at membrane potentials of approximately $-60 \mathrm{mV}$ and above. In the presence of TTX, the region of negative slope conductance between $-60 \mathrm{mV}$ and threshold was absent, and a subthreshold zero current point was established. Action potential-independent oscillations in the membrane potential were not observed, and application of hyperpolarizing current failed to reveal any subthreshold oscillation that might participate in the generation of tonic activity. Together, these data indicate that the subthreshold sodium current is critically involved in driving tonic firing. A subthreshold or persistent sodium current has been described in many classes of neurons (Crill, 1996), including 
neostriatal cholinergic cells (Chao and Alzheimer, 1995), and is sufficient to drive tonic activity in cerebellar Purkinje cells, subthalamic neurons, dopaminergic retinal amacrines, and neurons of the suprachiasmatic nucleus (Pennartz et al., 1997; Feigenspan et al., 1998; Bevan and Wilson, 1999; Raman and Bean, 1999). However, in cholinergic neurons, the spike AHP hyperpolarizes the neuron to a voltage range at which there is minimal sodium current activation, suggesting that at least one other subthreshold inward current is required for tonic firing.

Cholinergic cells possess the hyperpolarization-activated mixed cation conductance, $I_{\mathrm{h}}$ (Jiang and North, 1991; Kawaguchi, 1992, 1993). In many types of neurons and in heart, $I_{\mathrm{h}}$ is described as the pacemaker current because it provides a depolarizing influence and regulates the time course of rhythmic oscillatory activity (DiFrancesco, 1993; Maccaferri and McBain, 1996; Pape, 1996; Lüthi and McCormick, 1998b). Blockade of $I_{\mathrm{h}}$ in cholinergic neurons produced a profound reduction of firing rate and, in four of nine, neurons resulted in complete quiescence. Voltage-clamp data revealed that $I_{\mathrm{h}}$ was activated at all subthreshold voltages and that blockade of this current could give rise to a zero current point in the subthreshold range and therefore a stable resting membrane potential. The h-current was required for recovery from the AHP and provided a sufficient depolarizing influence to drive the membrane potential into the voltage range at which the sodium current became available. Although $I_{\mathrm{h}}$ was activated at all subthreshold voltages, it appeared to be insufficient to bring cholinergic cells to spike threshold in the absence of the subthreshold sodium current (see above). Thus, one possible explanation for the range of firing rates observed for cholinergic cells in vitro and the fact that some cholinergic cells do not exhibit spontaneous activity is that there is cell to cell variability in the magnitude of $I_{\mathrm{h}}$ and the sodium current, both of which are required to ensure that there is no zero current point in the subthreshold voltage range.

\section{Calcium-dependent potassium currents pace tonic firing}

The temporal and spatial calcium dynamics were investigated for both spontaneous firing and during spiking elicited by intracellular current injection using fluorescence microscopy and simultaneous electrical recording. Minimal alterations in fluorescence were observed throughout the subthreshold voltage range, including the depolarizing ramp to spike threshold, and almost all elevations in intracellular calcium appeared to be spike-triggered. Cholinergic cells do not seem to possess a significant T-type calcium current because elevations in intracellular calcium were not seen during rebound depolarizations after negative current injection and rebounds were altogether absent after blockade of the sodium current and $I_{\mathrm{h}}$. Spike-triggered calcium influx was therefore likely to be mediated by high voltage-activated calcium channels that appeared to be located in both the soma and dendrites because action potentials elicited simultaneous elevations in calcium in both locations. Calcium currents are therefore likely to play a secondary role in directly driving tonic firing but appear to be of primary importance in the maintenance of spontaneous activity by virtue of the apparent calcium-dependence of $I_{\mathrm{h}}$. The voltage range of activation of $I_{\mathrm{h}}$ can be shifted directly by calcium (Hagiwara and Irisawa, 1989; Lüthi and McCormick, 1998a) or indirectly through calciumdependent regulation of intracellular cAMP (DiFrancesco and Tortora, 1991; DiFrancesco and Mangoni, 1994; Lüthi and McCormick, 1999). Because minimal calcium entry appears to occur at subthreshold membrane potentials, we propose that blocking calcium channels hyperpolarizes cholinergic cells primarily by reducing the availability of $I_{\mathrm{h}}$. In addition, it is possible that the hyperpolarization may have also been contributed to by reduction of a subthreshold calcium current that was activated over the same voltage range as $I_{\mathrm{h}}$.

Calcium influx is pivotal in shaping the action potential and in the subsequent activation of both BK and SK type calciumdependent potassium channels, which are involved in spike repolarization and in the generation of the AHP, respectively. The action potential waveform exhibits a characteristic shoulder on the falling phase that is similar to that produced by the calcium component of the spike in inferior olivary neurons (Llinas and Yarom, 1981a,b). After calcium channel blockade, the spike width was reduced by $40 \%$ and the shoulder was absent, confirming the role of calcium in regulating the action potential time course and shape. The fact that rapid repolarization occurs in the absence of calciumdependent outward currents indicates that voltage-dependent potassium currents are activated during spiking. However, the Kv3 family of currents, Kv1.1, and KCNQ2 do not appear to be involved in spike repolarization because $1 \mathrm{~mm}$ TEA did not alter spike width during calcium channel blockade. Cholinergic neurons possess a well characterized A-type potassium current (Song et al., 1998), which is likely to play a role in the repolarization process. Under control conditions, spike-triggered calcium influx activated BK channels, which assisted in repolarization as they do in a diversity of neurons (Adams et al., 1982; Lancaster and Nicoll, 1987; Brown et al., 1990; Storm, 1990; Sah and McLachlan, 1992; Sah, 1996). Thus, both calcium-dependent and -independent outward currents appear to be required for spike termination and repolarization. In addition, spike-triggered calcium entry activates apamin-sensitive SK channels that underlie the single-spike AHP. The AHP is similar in pharmacological profile and duration to the medium AHP that has been described in many different types of cells (Pennefather et al., 1985; Schwindt et al., 1988; Shepard and Bunney, 1991; Sah and McLachlan, 1992; Kohler et al., 1996; Ping and Shepard, 1996; Sah, 1996; Bond et al., 1999). After calcium channel blockade and reduction of the AHP, there is a transformation in the firing properties of cholinergic cells with a threefold to fourfold increase in mean firing rate produced by current injections of $60-140 \mathrm{pA}$. The time course of the AHP, particularly the rate of deactivation, is therefore critical in determining the interspike interval. Furthermore, both direct calcium channel blockade or application of apamin, which blocks SK channels, could convert tonic firing to rhythmic bursting, indicating that the AHP is of pivotal importance in regulating the spontaneous firing pattern.

\section{The generation of tonic firing}

The intrinsic membrane properties of cholinergic cells provide an explanation for the origin of spontaneous tonic firing in cholinergic neurons. A TTX-sensitive fast sodium current generates the spike that activates calcium channels, and the resulting calcium influx shapes the action potential. Both voltage-dependent (probably A-type) and calcium-dependent (BK) potassium channels assist in repolarization, and spike-triggered calcium entry also activates SK channels, which produce the slow AHP. The AHP brings the neuron into a voltage range at which $I_{\mathrm{h}}$ produces a sufficient inward current to cause depolarization as the AHP decays. Finally, $I_{\mathrm{h}}$ depolarizes the membrane potential to a point at which the subthreshold sodium current is activated, the cell is driven to threshold, and the cycle is repeated. A possible explanation for burst firing is that reducing the amplitude of the AHP results in insufficient repolarization for the neuron to escape the voltage range of activation of the subthreshold sodium current. Consequently, a rapid succession of spikes are generated, and the burst is terminated by either calcium-dependent apamin-insensitive potassium channels and/or accumulation of a slowly activating noninactivating potassium current, the latter of which has been described for cholinergic cells (Song et al., 1998). Recovery from the interburst hyperpolarization would arise from activation of $I_{\mathrm{h}}$ and decay of the mechanism(s) responsible for the hyperpolarization.

\section{Implications for spike timing in TANs}

Unit recordings from awake, behaving monkeys have described a spectrum of firing patterns for TANs ranging from tonic regular or irregular firing to bursting. A very similar range of firing patterns is observed for cholinergic cells in vitro. Although synaptic inputs are clearly influential in regulating spike timing in cholinergic cells, we propose that the characteristic spike sequences described for TANs recorded in vivo are a natural product of the intrinsic membrane properties. Furthermore, we suggest that bursting may 
arise from neuromodulatory regulation of calcium influx, which controls the AHP, and that the persistent oscillatory activity of TANs detected in parkinsonian states could reflect a pathophysiological switch to burst firing mode.

\section{REFERENCES}

Adams PR, Constanti A, Brown DA, Clark RB (1982) Intracellular Ca ${ }^{2+}$ activates a fast voltage-sensitive $\mathrm{K}^{+}$current in vertebrate sympathetic neurones. Nature 296:746-749.

Aghajanian GK, Rasmussen K (1989) Intracellular studies in the facial nucleus illustrating a simple new method for obtaining viable motoneurons in adult rat brain slices. Synapse 3:331-338.

Akaike N, Harata N (1994) Nystatin perforated patch recording and its applications to analyses of intracellular mechanisms. Jpn J Physiol 44:433-473

Aosaki T, Graybiel AM, Kimura M (1994a) Effect of the nigrostriatal dopamine system on acquired neural responses in the striatum of behaving monkeys. Science 265:412-415.

Aosaki T, Tsubokawa H, Ishida A, Watanabe K, Graybiel AM, Kimura M (1994b) Responses of tonically active neurons in the primate's striatum undergo systematic changes during behavioral sensorimotor conditioning. J Neurosci 14:3969-3984.

Aosaki T, Kimura M, Graybiel AM (1995) Temporal and spatial characteristics of tonically active neurons of the primate's striatum. J Neurophysiol 73:1234-1252.

Apicella P, Scarnati E, Schultz W (1991) Tonically discharging neurons of monkey striatum respond to preparatory and rewarding stimuli. Exp Brain Res 84:672-675.

Bennett BD, Wilson CJ (1998) Synaptic regulation of action timing in neostriatal cholinergic interneurons. J Neurosci 18:8539-8549.

Bennett BD, Wilson CJ (1999) Spontaneous activity of neostriatal cholinergic interneurons in vitro. J Neurosci 19:5586-5596.

Bevan MD, Wilson CJ (1999) Mechanisms underlying spontaneous oscillation and rhythmic firing in rat subthalamic neurons. J Neurosci 19:7617-7628.

Bond CT, Maylie J, Adelman JP (1999) Small-conductance calciumactivated potassium channels. Ann NY Acad Sci 868:370-378.

Brown DA, Gahwiler BH, Griffith WH, Halliwell JV (1990) Membrane currents in hippocampal neurons. Prog Brain Res 83:141-160.

Calabresi P, Centonze D, Pisani A, Sancesario G, North RA, Bernardi G (1998) Muscarinic IPSPs in rat striatal cholinergic interneurones. J Physiol (Lond) 510:421-427.

Chao TI, Alzheimer C (1995) Do neurons from rat neostriatum express both a TTX-sensitive and a TTX-insensitive slow $\mathrm{Na}^{+}$current? J Neurophysiol 74:934-941.

Coetzee WA, Amarillo Y, Chiu J, Chow A, Lau D, McCormack T, Moreno H, Nadal MS, Ozaita A, Pountney D, Saganich M, Vega-Saenz de Miera E, Rudy B (1999) Molecular diversity of K+ channels. Ann NY Acad Sci 868:233-285.

Crill WE (1996) Persistent sodium current in mammalian central neurons. Annu Rev Physiol 58:349-362.

Crutcher MD, DeLong MR (1984) Single cell studies of the primate putamen. II. Relations to direction of movement and pattern of muscular activity. Exp Brain Res 53:244-258.

DiFrancesco D (1993) Pacemaker mechanisms in cardiac tissue. Annu Rev Physiol 55:455-472.

DiFrancesco D, Mangoni M (1994) Modulation of single hyperpolarization-activated channels $\left(i_{f}\right)$ by cAMP in the rabbit sino-atrial node. J Physiol (Lond) 474:473-482.

DiFrancesco D, Tortora P (1991) Direct activation of cardiac pacemaker channels by intracellular cyclic AMP. Nature 351:145-147.

Dodt HU, Zieglgansberger W (1990) Visualizing unstained neurons in living brain slices by infrared DIC-videomicroscopy. Brain Res 537:333-336.

Ebihara S, Shirato K, Harata N, Akaike N (1995) Gramicidin-perforated patch recording: GABA response in mammalian neurones with intact intracellular chloride. J Physiol (Lond) 484:77-86.

Feigenspan A, Gustincich S, Bean BP, Raviola E (1998) Spontaneous activity of solitary dopaminergic cells of the retina. J Neurosci 18:6776-6789.

Götz T, Kraushaar U, Geiger J, Lubke J, Berger T, Jonas P (1997) Functional properties of AMPA and NMDA receptors expressed in identified types of basal ganglia neurons. J Neurosci 17:204-215.

Graybiel AM, Aosaki T, Flaherty AW, Kimura M (1994) The basal ganglia and adaptive motor control. Science 265:1826-1831.

Hagiwara N, Irisawa H (1989) Modulation by intracellular $\mathrm{Ca}^{2+}$ of the hyperpolarization-activated inward current in rabbit single sino-atrial node cells. J Physiol (Lond) 409:121-141.

Hingtgen CM, Siemers E (1998) The treatment of Parkinson's disease: current concepts and rationale. Compr Ther 24:560-566.

Horn R, Marty A (1988) Muscarinic activation of ionic currents measured by a new whole-cell recording method. J Gen Physiol 92:145-159.

Jiang ZG, North RA (1991) Membrane properties and synaptic responses of rat striatal neurones in vitro. J Physiol (Lond) 443:533-553.
Kang Y, Kitai ST (1993) Calcium spike underlying rhythmic firing in dopaminergic neurons of the rat substantia nigra. Neurosci Res 18:195-207.

Kawaguchi Y (1992) Large aspiny cells in the matrix of the rat neostriatum in vitro: physiological identification, relation to the compartments and excitatory postsynaptic currents. J Neurophysiol 67:1669-1682.

Kawaguchi Y (1993) Physiological, morphological, and histochemical characterization of three classes of interneurons in rat neostriatum. J Neurosci 13:4908-4923.

Kimura M, Rajkowski J, Evarts E (1984) Tonically discharging putamen neurons exhibit set-dependent responses. Proc Natl Acad Sci USA 81:4998-5001.

Kohler M, Hirschberg B, Bond CT, Kinzie JM, Marrion NV, Maylie J, Adelman JP (1996) Small-conductance, calcium-activated potassium channels from mammalian brain. Science 273:1709-1714.

Korn SJ, Horn R (1989) Influence of sodium-calcium exchange on calcium current rundown and the duration of calcium-dependent chloride currents in pituitary cells, studied with whole cell and perforated patch recording. J Gen Physiol 94:789-812.

Kyrozis A, Reichling DB (1995) Perforated-patch recording with gramicidin avoids artifactual changes in intracellular chloride concentration. J Neurosci Methods 57:27-35.

Lancaster B, Nicoll RA (1987) Properties of two calcium-activated hyperpolarizations in rat hippocampal neurones. J Physiol (Lond) 389:187-203.

Lee K, Dixon AK, Freeman TC, Richardson PJ (1998) Identification of an ATP-sensitive potassium channel current in rat striatal cholinergic interneurones. J Physiol (Lond) 510:441-453.

Lev-Ram V, Miyakawa H, Lasser-Ross N, Ross WN (1992) Calcium transients in cerebellar Purkinje neurons evoked by intracellular stimulation. J Neurophysiol 68:1167-1177.

Liles SL (1985) Activity of neurons in putamen during active and passive movements of wrist. J Neurophysiol 53:217-236.

Llinas R, Yarom Y (1981a) Electrophysiology of mammalian inferior olivary neurones in vitro. Different types of voltage-dependent ionic conductances. J Physiol (Lond) 315:549-567.

Llinas R, Yarom Y (1981b) Properties and distribution of ionic conductances generating electroresponsiveness of mammalian inferior olivary neurones in vitro. J Physiol (Lond) 315:569-584.

Llinas R, Yarom Y (1986) Oscillatory properties of guinea-pig inferior olivary neurones and their pharmacological modulation: an in vitro study. J Physiol (Lond) 376:163-182.

Lüthi A, McCormick DA (1998a) Periodicity of thalamic synchronized oscillations: the role of $\mathrm{Ca}^{2+}$-mediated upregulation of $\mathrm{Ih}$. Neuron 20:553-563.

Lüthi A, McCormick DA (1998b) H-current: properties of a neuronal and network pacemaker. Neuron 21:9-12.

Lüthi A, McCormick DA (1999) Modulation of a pacemaker current through $\mathrm{Ca}^{2+}$-induced stimulation of cAMP production. Nat Neurosci 2:634-641.

Maccaferri G, McBain CJ (1996) The hyperpolarization-activated current (Ih) and its contribution to pacemaker activity in rat CA1 hippocampal stratum oriens-alveus interneurones. J Physiol (Lond) 497:119-130.

Magistretti J, Mantegazza M, Guatteo E, Wanke E (1996) Action potentials recorded with patch-clamp amplifiers: are they genuine? Trends Neurosci 19:530-534.

Mainen ZF, Joerges J, Huguenard JR, Sejnowski TJ (1995) A model of spike initiation in neocortical pyramidal neurons. Neuron 15:1427-1439.

Myers VB, Haydon DA (1972) Ion transfer across lipid membranes in the presence of gramicidin A. II. The ion selectivity. Biochim Biophys Acta 274:313-322.

Pape HC (1996) Queer current and pacemaker: the hyperpolarizationactivated cation current in neurons. Annu Rev Physiol 58:299-327.

Pennartz CM, Bierlaagh MA, Geurtsen AM (1997) Cellular mechanisms underlying spontaneous firing in rat suprachiasmatic nucleus: involvement of a slowly inactivating component of sodium current. J Neurophysiol 78:1811-1825.

Pennefather P, Lancaster B, Adams PR, Nicoll RA (1985) Two distinct $\mathrm{Ca}$-dependent $\mathrm{K}$ currents in bullfrog sympathetic ganglion cells. Proc Natl Acad Sci USA 82:3040-3044.

Ping HX, Shepard PD (1996) Apamin-sensitive $\mathrm{Ca}^{2+}$-activated $\mathrm{K}^{+}$channels regulate pacemaker activity in nigral dopamine neurons. NeuroReport 7:809-814.

Pisani A, Calabresi P, Centonze D, Marfia GA, Bernardi G (1999) Electrophysiological recordings and calcium measurements in striatal large aspiny interneurons in response to combined $\mathrm{O} 2 /$ glucose deprivation. J Neurophysiol 81:2508-2516.

Pisani A, Bonsi P, Centonze D, Calabresi P, Bernardi G (2000) Activation of D2-like dopamine receptors reduces synaptic inputs to striatal cholinergic interneurons. J Neurosci 20:RC69.

Raman IM, Bean BP (1999) Ionic currents underlying spontaneous action potentials in isolated cerebellar Purkinje neurons. J Neurosci 19:1663-1674.

Raz A, Feingold A, Zelanskaya V, Vaadia E, Bergman H (1996) Neuronal synchronization of tonically active neurons in the striatum of normal and parkinsonian primates. J Neurophysiol 76:2083-2088.

Rhee JS, Ebihara S, Akaike N (1994) Gramicidin perforated patch-clamp 
technique reveals glycine-gated outward chloride current in dissociated nucleus solitarii neurons of the rat. J Neurophysiol 72:1103-1108.

Rudy B, Chow A, Lau D, Amarillo Y, Ozaita A, Saganich M, Moreno H Nadal MS, Hernandez-Pineda R, Hernandez-Cruz A, Erisir A, Leonard C, Vega-Saenz de Miera E (1999) Contributions of Kv3 channels to neuronal excitability. Ann NY Acad Sci 868:304-343.

Sah P (1996) $\mathrm{Ca}^{2+}$-activated $\mathrm{K}^{+}$currents in neurones: types, physiological roles and modulation. Trends Neurosci 19:150-154.

Sah P, McLachlan EM (1992) Potassium currents contributing to action potential repolarization and the afterhyperpolarization in rat vagal motoneurons. J Neurophysiol 68:1834-1841.

Schrag A, Schelosky L, Scholz U, Poewe W (1999) Reduction of Parkinsonian signs in patients with Parkinson's disease by dopaminergic versus anticholinergic single-dose challenges. Mov Disord 14:252-255.

Schultz W, Romo R (1988) Neuronal activity in the monkey striatum during the initiation of movements. Exp Brain Res 71:431-436.

Schwindt PC, Spain WJ, Foehring RC, Stafstrom CE, Chubb MC, Crill WE (1988) Multiple potassium conductances and their functions in neurons from cat sensorimotor cortex in vitro. J Neurophysiol 59:424-449.

Shepard PD, Bunney BS (1991) Repetitive firing properties of putative dopamine-containing neurons in vitro: regulation by an apamin-sensitive $\mathrm{Ca}^{2+}$-activated $\mathrm{K}^{+}$conductance. Exp Brain Res 86:141-150.

Song WJ, Tkatch T, Baranauskas G, Ichinohe N, Kitai ST, Surmeier DJ (1998) Somatodendritic depolarization-activated potassium currents in rat neostriatal cholinergic interneurons are predominantly of the A type and attributable to coexpression of Kv4.2 and Kv4.1 subunits. J Neurosci 18:3124-3137.

Storm JF (1990) Potassium currents in hippocampal pyramidal cells. Prog Brain Res 83:161-187.

Stuart GJ, Dodt HU, Sakmann B (1993) Patch-clamp recordings from the soma and dendrites of neurons in brain slices using infrared video microscopy. Pflügers Arch 423:511-518.

Watanabe K, Kimura M (1998) Dopamine receptor-mediated mechanisms involved in the expression of learned activity of primate striatal neurons. J Neurophysiol 79:2568-2580.

White JA, Sekar NS, Kay AR (1995) Errors in persistent inward currents generated by space-clamp errors: a modeling study. J Neurophysiol 73:2369-2377.

White JA, Rubinstein JT, Kay AR (2000) Channel noise in neurons Trends Neurosci 23:131-137.

Wilson CJ (1993) The generation of natural firing patterns in neostriatal neurons. In: Chemical signalling in the basal ganglia, Progress in brain research 99, pp 277-297. Oxford: Elsevier.

Wilson CJ, Chang HT, Kitai ST (1990) Firing patterns and synaptic potentials of identified giant aspiny interneurons in the rat neostriatum. J Neurosci 10:508-519.

Yan Z, Surmeier DJ (1997) D5 dopamine receptors enhance $\mathrm{Zn}^{2+}$. sensitive $\mathrm{GABA}_{\mathrm{A}}$ currents in striatal cholinergic interneurons through a PKA/PP1 cascade. Neuron 19:1115-1126. 